\title{
The Effect of Divalent Metal Ions on the Temperature Stability of Poly(I:C) Duplex
}

\author{
Evgeniya Usenko $\left(D\right.$, Vladimir Valeev, Alexander Glamazda ${ }^{(D)}$, and Victor Karachevtsev \\ B. Verkin Institute for Low Temperature Physics and Engineering of NAS of Ukraine, 47 Nauky Ave., Kharkiv 61103, Ukraine \\ Correspondence should be addressed to Evgeniya Usenko; usenko74@gmail.com and Alexander Glamazda; alex.glamazda@ \\ gmail.com
}

Received 2 April 2020; Revised 24 May 2020; Accepted 3 June 2020; Published 27 June 2020

Academic Editor: Jeongkwon Kim

Copyright (C) 2020 Evgeniya Usenko et al. This is an open access article distributed under the Creative Commons Attribution License, which permits unrestricted use, distribution, and reproduction in any medium, provided the original work is properly cited.

The effect of divalent ions on the thermal stability of the double-stranded polynucleotide polyinosinic:polycytidylic acid (poly(I: C)) in a buffer solution ( $\mathrm{pH} 7$ ) was studied by UV absorption spectroscopy and thermal denaturation by measuring the absorbance at $260 \mathrm{~nm}$. The concentration dependence of the polynucleotide melting temperature $\left(T_{\mathrm{m}}\right)$ in the presence of metal ions $\left(2.5 \times 10^{-6}-10^{-2} \mathrm{M}\right)$ was obtained. It was found that the duplex thermal stability grew gradually upon an increase of $\mathrm{Ca}^{2+}$ and $\mathrm{Mn}^{2+}$ concentration. The thermal stability of the duplex in the presence of $\mathrm{Cd}^{2+}, \mathrm{Ni}^{2+}$, and $\mathrm{Zn}^{2+}$ rises up to an ion concentration of about $10^{-4} \mathrm{M}$ and further falls. In contrast to these ions, the addition of $\mathrm{Cu}^{2+}$ to the solution leads to a sharp decline in $\mathrm{T}_{\mathrm{m}}$ of the duplex at a concentration above $10^{-5} \mathrm{M}$. The observed difference in the influence of metal ions on the poly(I:C) thermal stability is explained by the different affinity of these ions to both the phosphate groups and the nitrogenous bases of the polynucleotides. Based on the analysis of the $T_{\mathrm{m}}$ concentration dependence, the dominant binding of each ion to the specific polynucleotide components was proposed.

\section{Introduction}

Interest in studying the conformational state and the stability of polynucleotides of RNA family is caused by their biological functionality, their use in human disease treatments, and the possibility of using them as biomarkers, drug targets, and promising elements for nanoelectronics and nanobiosensors $[1,2]$. In particular, it is known that the double-stranded (ds) biopolymer polyinosinic:polycytidylic acid (poly(I:C)) (Figure 1) is used for the treatment of certain viral diseases as a potent agent that induces the interferon formation [3]. This duplex is characterized by the substitution of guanine-cytosine for inosine-cytosine pairs during replication or transcription without significant changes in the structural parameters of the helix [4]. The random substitution can lead to point mutations. The application of the targeted one allows using oligo- and polynucleotides containing inosine monophosphate (IMP) for solving problems of genetic engineering [4]. In addition, poly(I:C) is included in the anticodon of some tRNAs (for example, valine) [5].
Divalent metal ions play an important role in the functionality and the conformation stability of biopolymers [6]. The numerous data on metal complexes of the natural DNA and double-stranded homopolynucleotides containing pairs of canonical nitrogenous bases (adenine-thymine and guanine-cytosine) are already available [1, 7-16]. It is known that the main binding sites of metal ions to polynucleotides are oxygen atoms of phosphate groups, as well as nitrogen or oxygen atoms of nitrogenous bases [10,12-14]. It is shown that alkali and alkaline earth metal ions interact predominantly with phosphate groups resulting in stabilization of the structure of nucleic acids. The ions of transition metals interact with both phosphate groups and nucleic acid bases inducing the destabilization of the nucleic acid structure $[10,12-14]$.

At the moment, the information about the effect of metal ions on the thermal stability of poly(I:C) is very limited. Previously, the effect of divalent ions $\left(\mathrm{Cu}^{2+}, \mathrm{Cd}^{2+}, \mathrm{Mg}^{2+}\right.$, $\mathrm{Ni}^{2+}$, and $\mathrm{Co}^{2+}$ ) on the helical structure of poly(I:C) was studied by various spectroscopic methods [17-20]. However, 


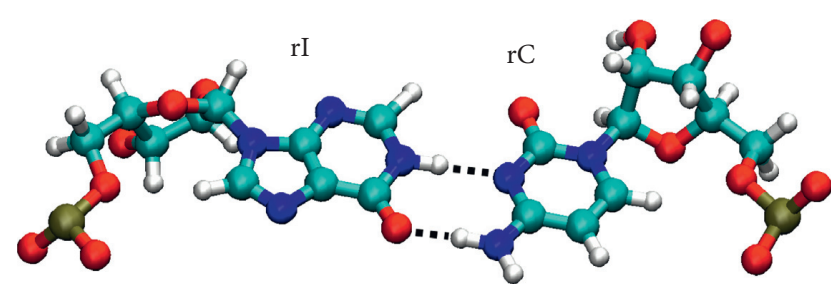

Figure 1: Hybridized poly(I:C) polynucleotide structure with Watson-Crick base pairing. Blue balls: $\mathrm{N}$; green balls: C; gray balls: $\mathrm{H}$; red balls: O; mustard balls: $\mathrm{P}$.

there was no detailed information about the influence of the divalent metal ions on the thermal stability of poly(I:C).

In particular, it was shown in [17] that $\mathrm{Cu}^{2+}$ destroys the helical structure of poly(I:C), while $\mathrm{Cd}^{2+}$ increases its thermal stability. Melting curves for a few ion concentrations were studied: (a) $6.3 \times 10^{-5} \mathrm{M}$ and $1.5 \times 10^{-4} \mathrm{M}$ of $\mathrm{Cu}^{2+}$; (b) $1.1 \times 10^{-4} \mathrm{M}$ and $2.1 \times 10^{-4} \mathrm{M}$ of $\mathrm{Cd}^{2+}$.

The influence of $\mathrm{Cu}^{2+}$ on the stability of poly(I:C) was analyzed by Eichhorn and Tarien [18]. They studied the kinetics of poly(I:C) formation from two single-stranded polynucleotides polyI and polyC. It was shown that, at the ion concentration below the phosphate group concentration, $\mathrm{Cu}^{2+}$ had no effect on the poly(I:C) stability, and at the same time, at an ion concentration above that of the phosphate group, destruction of the poly(I:C) structure was revealed.

The binding of $\mathrm{Ni}^{2+}, \mathrm{Mg}^{2+}$, and $\mathrm{Co}^{2+}$ to poly(I:C) was studied by UV spectrophotometry at a fixed temperature of $25^{\circ} \mathrm{C}$ [19]. Differential absorption spectra of poly(I:C) in the presence of $\mathrm{Ni}^{2+}$ were obtained and the binding constants of this ion with the polynucleotides were calculated. It was found that $\mathrm{Mg}^{2+}$ electrostatically (outer sphere) interacts with poly(I:C), while $\mathrm{Ni}^{2+}$ (in the concentration range of $10^{-5}-3.8 \times 10^{-4} \mathrm{M}$ and at low ionic strength of $0.01 \mathrm{M}$ ) can bind to N7 of purine bases (inner sphere) as well as to the oxygen atoms in the phosphate group.

We studied the influence of the $\mathrm{Mg}^{2+}$ concentration, which varied in wide range between $2 \times 10^{-6}$ and $7 \times 10^{-3} \mathrm{M}$, on the thermal stability of poly(I:C) in buffer solution close to physiological one $\left(0.1 \mathrm{M} \mathrm{Na}^{+}, \mathrm{pH} 7\right)$ using the differential UV spectroscopy [20]. It was shown that the increase of the $\mathrm{Mg}^{2+}$ concentration leads to an increase in $T_{\mathrm{m}}$ and to a decrease in the light absorption intensity (hypochromic effect). It was supposed that $\mathrm{Mg}^{2+}$ interacts with $\pi$-electrons of hypoxanthine or cytosine rings (cation- $\pi$ interaction). When the $\mathrm{Mg}^{2+}$ concentration reaches the critical value of $10^{-4} \mathrm{M}, T_{\mathrm{m}}$ decreases cooperatively and the light absorption intensity increases up (it is a hyperchromic effect that is opposite to a hypochromic one) to values close to the observed one in the absence of $\mathrm{Mg}^{2+}$. Thus, the effect of temperature on the stability of poly(I:C) was studied in detail only for $\mathrm{Mg}^{2+}[20]$, while for $\mathrm{Cu}^{2+}$ and $\mathrm{Cd}^{2+}$, it was considered only in a narrow concentration range [17].

The present work focuses on studying and comparably analyzing the effect of divalent ions $\left(\mathrm{Cu}^{2+}, \mathrm{Cd}^{2+}, \mathrm{Ca}^{2+}, \mathrm{Mn}^{2+}\right.$, $\mathrm{Ni}^{2+}$, and $\mathrm{Zn}^{2+}$ ) on the thermal stability of poly(I:C) under conditions close to physiological ones $\left(0.1 \mathrm{M} \mathrm{Na}^{+}, \mathrm{pH} 7\right)$ in a wide ion concentration range (between $2.5 \times 10^{-6}$ and $\left.10^{-2} \mathrm{M}\right)$. We have found gradual growth of the poly(I:C) thermal stability upon an increase of the $\mathrm{Ca}^{2+}$ and $\mathrm{Mn}^{2+}$ within the studied concentration range. By contrast, the thermal stability of poly(I:C) in the presence of $\mathrm{Cd}^{2+}, \mathrm{Ni}^{2+}$, and $\mathrm{Zn}^{2+}$ demonstrated a growth until an ion concentration of about $10^{-4} \mathrm{M}$ and a further decline. The addition of $\mathrm{Cu}^{2+}$ to the solution led to a sharp decrease in $T_{m}$ of the duplex at a concentration above $10^{-5} \mathrm{M}$. The various characteristics of the $\mathrm{Mt}^{2+}$ effect on the poly(I:C) thermal stability are discussed in terms of the different affinity of these ions to both the phosphate groups and the nitrogenous bases of the polynucleotides.

\section{Materials}

The poly(I:C) was prepared by dissolving polyI and polyC (Sigma, USA) at a $1: 1$ ratio in a buffer solution containing $0.001 \mathrm{M}$ sodium cacodylate $\left(\left(\mathrm{CH}_{3}\right)_{2} \mathrm{AsO}_{2} \mathrm{Na} \times 3 \mathrm{H}_{2} \mathrm{O}\right)$ (Serva, Germany) and $0.099 \mathrm{M} \mathrm{NaCl}$ at $\mathrm{pH}$ 7. In order to complete the poly(I:C) formation, the solution with the polynucleotides (phosphorus ion concentration [P]: 0.008-0.01 M) was kept for 120 hours at $4^{\circ} \mathrm{C}$. Before carrying out the thermal studying, the poly $(\mathrm{I}: \mathrm{C})$ concentration was brought to $[\mathrm{P}]=$ $2 \times 10^{-5} \mathrm{M}\left(\right.$ at $\left.\mathrm{T}_{0}=23.5^{\circ} \mathrm{C}\right)$. Such a small concentration of the polymer was chosen to exclude the poly(I:C) aggregation which can occur at high metal ion concentrations. The $[\mathrm{P}]$ value was estimated by analyzing the intensity of UV absorption maximum (at $\lambda=260 \mathrm{~nm}$ ) of the polymer and using the molar extinction coefficient $\varepsilon=4800 \mathrm{M}^{-1} \times \mathrm{cm}^{-1}$ [21].

We have used chemically pure salts of $\mathrm{NaCl}, \mathrm{ZnCl}_{2}$ $\times 4 \mathrm{H}_{2} \mathrm{O}, \quad \mathrm{CuCl}_{2} \times 2 \mathrm{H}_{2} \mathrm{O}, \mathrm{CaCl}_{2} \times 6 \mathrm{H}_{2} \mathrm{O}, \quad \mathrm{MnCl}_{2} \times 4 \mathrm{H}_{2} \mathrm{O}$, $\mathrm{NiCl}_{2} \times 6 \mathrm{H}_{2} \mathrm{O}$, and $\mathrm{CdCl}_{2} \times 2.5 \mathrm{H}_{2} \mathrm{O}$ (Reachim, Russia) in all experiments.

The concentration of metal ions $\left(\left[\mathrm{Mt}^{2+}\right]\right)$ added to the solution was determined by weight and controlled by the complexometric titration. The error in the determination of $\left[\mathrm{Mt}^{2+}\right]$ and $[\mathrm{P}]$ was less than $0.5 \%$.

\section{Methods}

3.1. UV Spectroscopy. In the present work, we have studied the effect of divalent ions $\mathrm{Cu}^{2+}, \mathrm{Cd}^{2+}, \mathrm{Ca}^{2+}, \mathrm{Mn}^{2+}, \mathrm{Ni}^{2+}$, and $\mathrm{Zn}^{2+}$ on the thermal stability of ds poly(I:C) in a buffer solution ( $\mathrm{pH} 7$ ) by using UV absorption spectroscopy. The UV spectra were recorded with UV-visible spectrophotometer (Specord M40, Carl Zeiss Jena, Germany). The absorption spectrum of poly(I:C) has two maxima located at $\lambda=248 \mathrm{~nm}$ and $\lambda=269 \mathrm{~nm}$ (Figure 2(a)). The first maximum corresponds to the absorption of polyI while the second one is assigned to the polyC absorption.

The method of UV spectroscopy is very sensitive to helix-coil transformation in polynucleotides caused by the destruction of the polymer ordering structure. The change in the conformation of nucleic acids occurs under the influence of various factors (for example, temperature, ionic conditions) and causes significant changes in the UV absorption spectrum [22]. In a double helix, nitrogenous bases stack one above the other. The extinction coefficient of a double helix depends on mutual orientation of the intrinsic dipole 


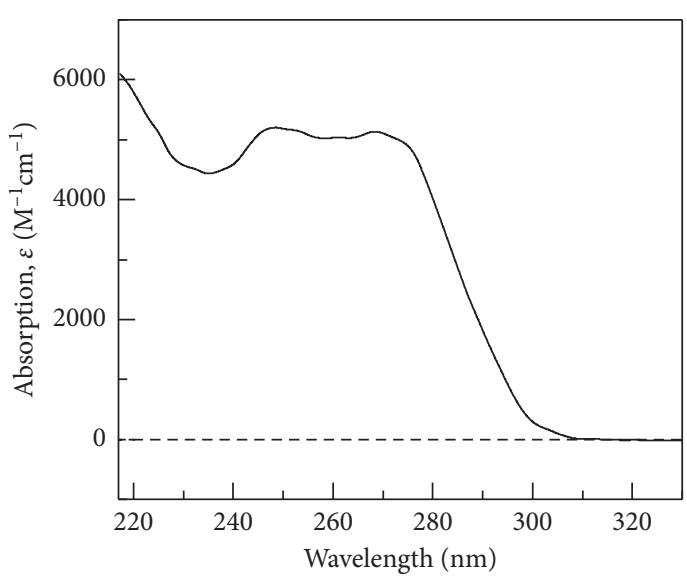

(a)

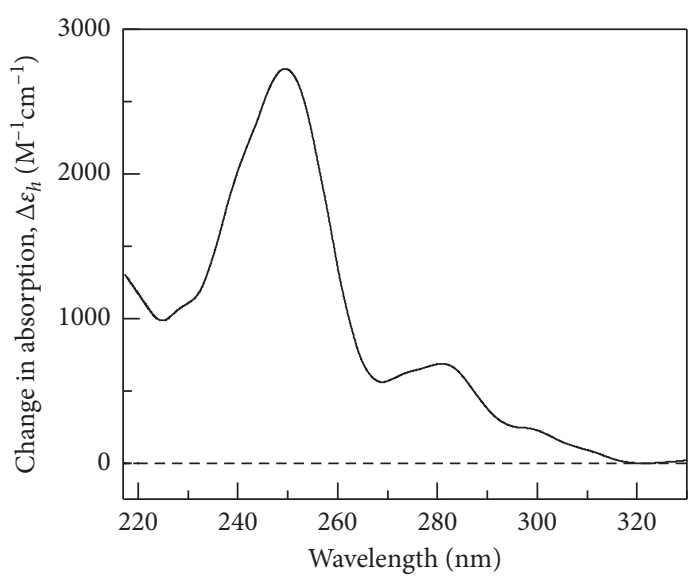

(b)

Figure 2: (a) Absorption spectrum of poly(I:C) polynucleotide and (b) its change induced by the heating from $20^{\circ} \mathrm{C}$ to $92^{\circ} \mathrm{C}$.

moments of stacking nitrogenous bases. If the moments are collinear, the light absorption will decrease (hypochromism). If the moments are canted, the light absorption will increase (hyperchromism).

3.2. Thermal Denaturation. Upon increasing the temperature, the ordered structure of the polynucleotide undergoes a denaturation transition. As a result, the polymer forms loops which appear because of breaking some $\mathrm{H}$-bonds between the paired bases. When the temperature reaches a value close to $T_{\mathrm{m}}$, the number of the helical regions is equal to the number of the untwisted regions. In other words, $T_{\mathrm{m}}$ is the temperature at which $50 \%$ of a DNA sequence is hybridized into a duplex, and the other $50 \%$ is present as single strands. A further increase in the temperature leads to a strong shift of equilibrium towards the increase of the fraction of the single strands. This process is accompanied by an increase of the intensity of UV absorption. The dynamics of this increase stops when the double helix of the biopolymer is completely disordered. This process is called the melting. The melting curve describes the dependence of UV absorption intensity on temperature.

The melting curves of the polynucleotides with different $\mathrm{Mt}^{2+}$ concentrations were recorded with spectrophotometer at fixed wavelength $\lambda_{\mathrm{m}}=248 \mathrm{~nm}$ that corresponds to the maximum absorption of polyI. We have used the laboratory software allowing to perform the registration of the melting curves as the temperature dependence of the hyperchromicity coefficient: $h(T)=\left[\Delta A(T) / A_{T_{0}}\right]_{v \mathrm{~m}}$, where $\Delta A(T)$ is a change in the optical density of poly(I:C) solution upon heating and $A_{T_{o}}$ is the optical density at $T=T_{\mathrm{o}}$. Thus, $h(T)$ is the quantitative characteristic of hyperchromism. The registration of the absorption intensity was carried out using the double-cuvette scheme: identical solutions of polynucleotides or their complexes with $\mathrm{Mt}^{2+}$ were placed in both channels of the spectrophotometer. The reference cuvette was thermostated at $T=T_{\mathrm{o}} \pm 0.5^{\circ} \mathrm{C}$, while the sample cuvette was slowly heated at a rate of $0.25^{\circ} \mathrm{C} / \mathrm{min}$ from 20 to $92^{\circ} \mathrm{C}$.
We registered the spectrum $\Delta \varepsilon_{h}(\nu)=\Delta A_{h}(\nu) / P$ at $T=92^{\circ} \mathrm{C}$, where $\Delta \varepsilon_{h}$ is the change in absorption due to the helix-coil transition and $\Delta A_{h}(\nu)$ is the change in the optical density of the solution upon heating (Figure 2(b)). We have revealed that the shape of the $\Delta \varepsilon_{h}(v)$ spectrum is independent of the ion concentration.

\section{Results and Discussion}

4.1. Poly(I:C) Melting Curves. Temperature dependence of hyperchromic coefficient of poly(I:C) in the presence of different $\mathrm{Mt}^{2+}$ is shown in Figures 3(a) and 3(c). The melting curve can be decomposed into three segments. A-B segment describes the starting of the polymer melting from the ends [23] or the helical sections of the single-stranded polyC or polyI which do not form complementary pairs due to different lengths of the initial polymers. B-C segment is assigned to the duplex denaturation into two single strands (transition $2 \longrightarrow 1$ ). This section is characterized by the derivative $\mathrm{d} h / \mathrm{d} T \sim(0.2 \pm 0.07) \operatorname{grad}^{-1}$ (Figures $3(\mathrm{~b})$ and $\left.3(\mathrm{~d})\right)$. The derivative has a sharp maximum indicating that the polymer melting occurs for short temperature interval. Note that S-like form of the $h(T)$ curve is evidence that the melting of duplex is a cooperative process. C-D segment marks the end of the duplex denaturation [23].

4.2. Temperature Stability of Poly(I:C) Duplex in the Presence of Different Concentrations of $\mathrm{Mt}^{2+}$. We performed the comparative analysis of the poly(I:C) thermal stability as function of ion concentration (Figure 4). The figure shows that the $T_{\mathrm{m}}$ dependence of poly(I:C) with $\mathrm{Mn}^{2+}$ practically coincides with that of $\mathrm{Ca}^{2+}$. Note that an increase in $T_{\mathrm{m}}$ with increasing ion concentration is observed in the whole range of concentrations $\left(2.5 \times 10^{-6}-10^{-2} \mathrm{M}\right)$ of $\mathrm{Mn}^{2+}$ and $\mathrm{Ca}^{2+}$. For other ions, the $T_{\mathrm{m}}$ dependence shows a more complex behavior (Figure 4). In the melting experiments with $\mathrm{Cd}^{2+}$, $\mathrm{Zn}^{2+}$, and $\mathrm{Ni}^{2+}$, an increase in $T_{\mathrm{m}}$ is observed up to a concentration of $\sim 10^{-4} \mathrm{M}$. The increase of $T_{\mathrm{m}}$ in the presence of $\mathrm{Cd}^{2+}$ and $\mathrm{Zn}^{2+}$ is $2.5^{\circ} \mathrm{C}$; for $\mathrm{Ni}^{2+}$, it is $5.5^{\circ} \mathrm{C}$ (for $\mathrm{Mn}^{2+}$ and 


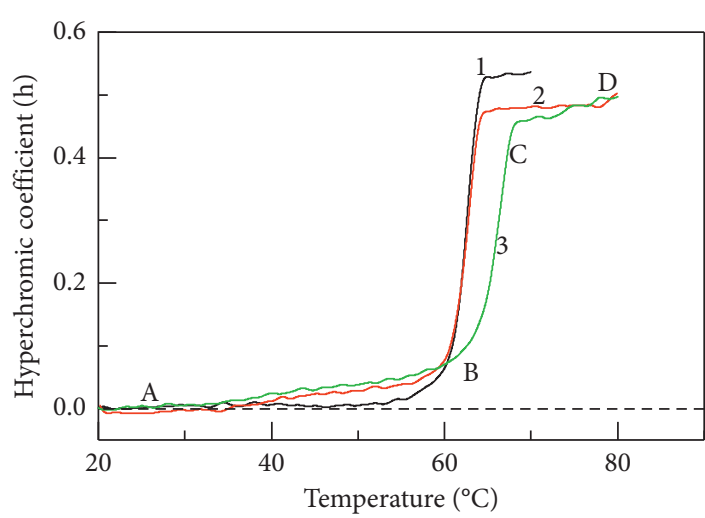

(a)

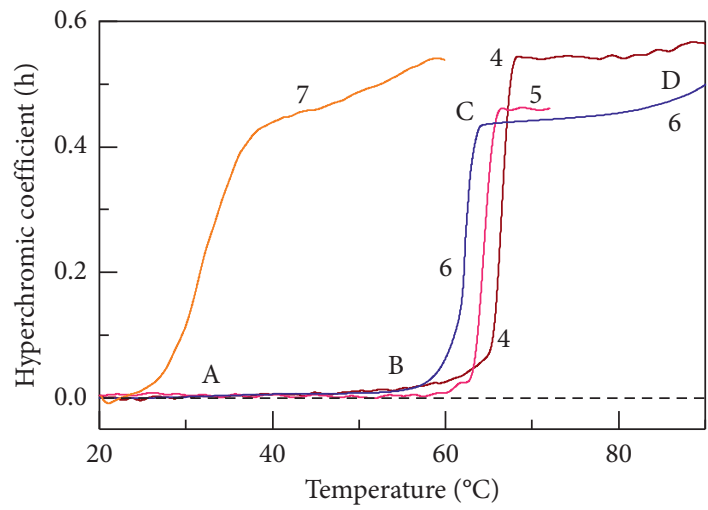

(c)

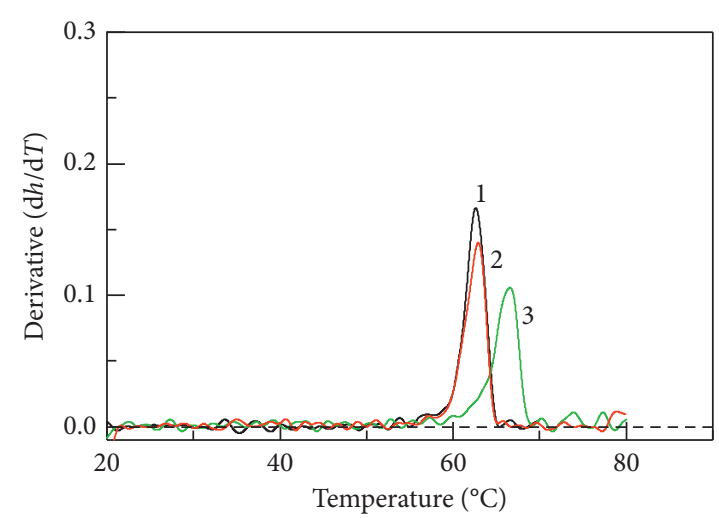

(b)

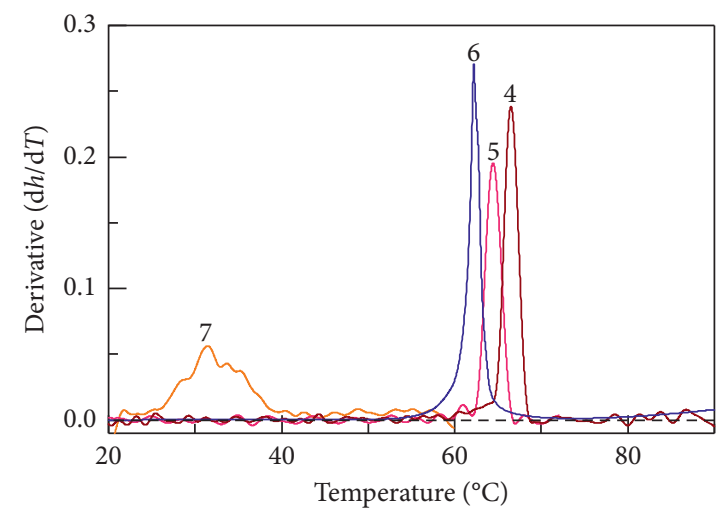

(d)

Figure 3: (a) Temperature dependence of hyperchromic coefficient of poly(I:C) in the presence of $\mathrm{Mt}^{2+}: 1-\left[\mathrm{Mt}^{2+}\right]=0,2-7.4 \times 10^{-5} \mathrm{M}^{2}$ $\mathrm{Ca}^{2+}, 3-1.8 \times 10^{-4} \mathrm{M} \mathrm{Mn}^{2+}$; (b) the derivatives of the curves presented in (a); (c) $h(T)$ curves of poly(I:C) doped with $\mathrm{Mt}^{2+}: 4-5 \times 10^{-4} \mathrm{M}^{2}$ $\mathrm{Ni}^{2+} ; 5-10^{-4} \mathrm{M} \mathrm{Zn}^{2+} ; 6-3 \times 10^{-4} \mathrm{M} \mathrm{Cd}^{2+} ; 7-5 \times 10^{-5} \mathrm{M} \mathrm{Cu}^{2+}$; (d) the derivatives of $h(T)$ presented in (c).

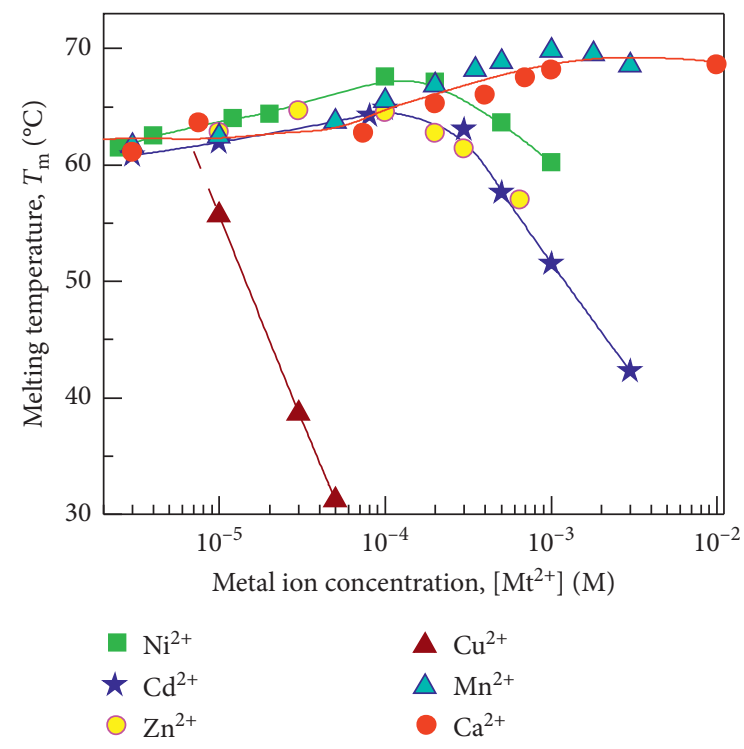

FIGURE 4: Dependence of the melting temperatures $\left(T_{\mathrm{m}}\right)$ of poly(I: C) on the $\mathrm{Mt}^{2+}$ concentrations.

$\mathrm{Ca}^{2+}$, it is about $\left.8^{\circ} \mathrm{C}\right)$. A further increase in the ion concentration leads to a reduction in the thermal stability of poly(I: C). In contrast to these ions, sharp suppression of the poly(I:C) thermal stability is observed in the presence of $\left[\mathrm{Cu}^{2+}\right]>10^{-5} \mathrm{M}$. For example, the $T_{\mathrm{m}}$ value of poly(I:C) with $\mathrm{Cu}^{2+}$ is $31.5^{\circ} \mathrm{C}$ at $5 \times 10^{-5} \mathrm{M}$ (Figure 4 ). We could not measure the $T_{\mathrm{m}}$ dependence in the presence of $\left[\mathrm{Ni}^{2+}\right]>10^{-3} \mathrm{M},\left[\mathrm{Zn}^{2+}\right]>6.5 \times 10^{-4} \mathrm{M}$, and $\left[\mathrm{Cu}^{2+}\right]>5 \times 10^{-5} \mathrm{M}$ because of the appearance of the light scattering that distorts the shape of the melting curves. In our opinion, this light scattering is caused by polymer aggregation induced by ions. Note that the data presented in this article were taken under equilibrium conditions.

It is known that the Coulomb interaction of metal ions with negative charges located on the oxygen atoms of the phosphate groups of single- or double-stranded polynucleotides leads to an increase in their thermal stability $[9,10,23-26]$. This interaction is a characteristic for all metal ions. However, transition metal ions, in contrast to alkali and alkaline earth metal ions, interact with phosphate groups as well as nucleic acid bases that destabilize the polynucleotide structure [7]. Thus, we can assume that the increase in $T_{\mathrm{m}}$ observed in our case after adding $\mathrm{Mn}^{2+}$ and $\mathrm{Ca}^{2+}$ in the solution is caused by the fact that the interaction of these ions with negatively charged oxygen atoms of phosphate groups is dominant. The decrease in $T_{\mathrm{m}}$ observed in the presence of $\mathrm{Zn}^{2+}, \mathrm{Ni}^{2+}$, and $\mathrm{Cd}^{2+}$ at a concentration higher than $10^{-4} \mathrm{M}$ is, apparently, due to the 
predominant interaction of these ions with the nitrogenous bases. This significantly weakens the polymer thermal stability. The dramatic decrease in $T_{\mathrm{m}}$ for $\mathrm{Cu}^{2+}$ was revealed at ion concentrations higher than $10^{-5} \mathrm{M}$ caused by the destruction of poly(I:C) duplex structure [18].

We showed earlier $[11,23]$ that the change in the characteristics of $T_{\mathrm{m}}$ is caused by the ratio between the binding constants of the ions to the two- and singlestranded conformations of the polynucleotides. According to the theory of equilibrium binding of polynucleotides to small molecular species [18], the value of change in $T_{\mathrm{m}}$ at the $2 \longrightarrow 1$ transition should be proportional to the ratio:

$$
\delta T_{\mathrm{m} 2 \longrightarrow 1} \sim \frac{1}{\Delta H_{21}} \ln \frac{K_{2}}{K_{1}},
$$

where $\delta T_{\mathrm{m} 2 \longrightarrow 1}=T_{\mathrm{m}}-T_{\mathrm{m} 0}, T_{\mathrm{m} 0}$ is the melting temperature of poly(I:C) without adding the metal ions $\left(T_{\mathrm{m} 0}=62.5^{\circ} \mathrm{C}\right)$, $\Delta \mathrm{H}_{21}$ is the enthalpy of the $2 \longrightarrow 1$ transition, $K_{2}$ is the effective binding constant of $\mathrm{Mt}^{2+}$ to ds poly(I:C), and $K_{1}$ is the effective binding constant of $\mathrm{Mt}^{2+}$ to single-stranded polyI and polyC.

Because $\Delta H_{21}>0$ [26], the necessary condition for $\delta \mathrm{T}_{\mathrm{m} 2 \longrightarrow 1}>0$ must be fulfilled: $K_{2}>K_{1}$. The decrease in $T_{\mathrm{m}}$ of the $2 \longrightarrow 1$ transition in the presence of $\mathrm{Ni}^{2+}, \mathrm{Cd}^{2+}, \mathrm{Zn}^{2+}$, and $\mathrm{Cu}^{2+}$ is probably due to the fact that $K_{1}>K_{2}$. The stronger destabilizing effect of $\mathrm{Cu}^{2+}$ on the thermal stability of poly(I:C) may be caused by the difference between $K_{1}$ and $K_{2}$ that is much more than that for $\mathrm{Ni}^{2+}, \mathrm{Cd}^{2+}$, and $\mathrm{Zn}^{2+}$. Another possible cause of this destabilizing effect is the stronger (regarding other ions) affinity of $\mathrm{Cu}^{2+}$ to the nitrogenous bases of the two- and one-stranded polynucleotides.

The studied ions destabilizing the structure of poly(I:C) can be arranged in the sequence $\mathrm{Cu}^{2+}>\mathrm{Cd}^{2+} \geq$ $\mathrm{Zn}^{2+}>\mathrm{Ni}^{2+}>\mathrm{Mn}^{2+}$. From this order, it follows that $\mathrm{Mn}^{2+}$ has the least destabilizing effect on duplex. It is known that all metal ions containing $d$-electrons in the outer orbitals ( $d$-ions) demonstrate a dominant interaction with the nitrogenous bases of polynucleotides $[8,27,28]$ that is especially pronounced at high ion concentrations. It would be expected that binding $\mathrm{Mn}^{2+}$ with a duplex should be similar to that observed for other $d$-ions. However, as shown above, the $T_{\mathrm{m}}$ dependence for this ion practically coincides with the $T_{\mathrm{m}}$ one in the presence of $\mathrm{Ca}^{2+}$ that mainly binds with oxygen ions of phosphate groups. Thus, we can suppose that the thermal stability of poly(I:C) is predominantly determined by the Coulomb interaction of $\mathrm{Mn}^{2+}$ with negatively charged oxygen atoms of phosphate groups.

The analysis of the $T_{\mathrm{m}}$ dependence allows us to estimate the concentration range in which a contribution of the interaction of certain metal ion with phosphate groups or with nitrogenous bases of poly(I:C) prevails. It is known that the interaction of $\mathrm{Ca}^{2+}$ with poly(I:C) is mainly with phosphate groups $[12,27]$. This interaction leads to a monotonous increase in the poly(I:C) thermal stability. For other ions, the $T_{\mathrm{m}}$ dependence presented in Figure 4 can be approximated by a superposition of two curves assigned to the interaction of certain ion with phosphates and/or with nitrogenous bases of poly(I:C). The component describing the interaction with the nitrogenous bases can be found from the following equation: $\left(\mathrm{d} T_{\mathrm{m}}\right)_{\mathrm{N}}=T_{\mathrm{m}}\left(\left[\mathrm{Mt}^{2+}\right]\right)-T_{\mathrm{m}}\left(\left[\mathrm{Ca}^{2+}\right]\right)$. To write this equation, we assume that the contribution of the interaction of each studied ion with the phosphate group to the $T_{\mathrm{m}}$ dependence is similar to $\mathrm{Ca}^{2+}$. The change in the thermal stability of poly(I:C) induced by $\mathrm{Mt}^{2+}$ due to binding with two different sites of the polymer is shown in Figure 5. The biggest destabilizing effect is observed for $\mathrm{Cu}^{2+}$ and the smallest one for $\mathrm{Ni}^{2+}$ at high concentrations. The influence of $\mathrm{Cd}^{2+}$ and $\mathrm{Zn}^{2+}$ on the thermal stability of poly(I:C) is approximately the same.

It is known that the thermal stability of metal complexes is influenced not only by the type of the ions and their concentration, but also the radius. As shown in [10], the highest thermal stability is observed for DNA complexes with metal ions whose ion radius $(r)$ is $0.7 \AA \leq r \leq 0.9 \AA$. As noted above, metal ions can interact with phosphates and nitrogenous bases (inner sphere or outer sphere) and also can be intercalated between pairs of nitrogenous bases. It has been shown in previous papers $[12,29]$ that the size of the ion plays an important role in the case of intercalation: the intercalation cannot be possible for steric reasons if $r \sim 1 \AA[12,29]$. This circumstance is also the reason for the lack of DNA metallization [29] in the presence of $\mathrm{Cd}^{2+}(r=0.97 \AA$ [30]). According to existing models, the metallization arises from the replacement of the imino protons in adeninethymine and cytosine-guanine pairs of double helix by $\mathrm{Mt}^{2+}$ [28]. An essential condition for the realization of the metallization is local opening of the double helix. The metallization is the most effective in the presence of $\mathrm{Zn}^{2+}$, $\mathrm{Ni}^{2+}$, and $\mathrm{Co}^{2+}$ having $r \leq 0.74 \AA$ [2]. These ions interact with both phosphate groups and nitrogenous bases of poly(I:C). In our case for ions with radius arranged in the interval of $0.7-0.9 \AA$, the dominant factor playing the basic role in the interaction with poly(I:C) is not the ion radius but rather the concentration of $\mathrm{Mt}^{2+}$ and the nature of metal ion. Thus, the results of the work show that metal cations can be an effective tool to tune the thermal stability of polynucleotides. The obtained experimental data about the thermal stability of poly(I:C) in the presence of cations expand our understanding of the molecular mechanisms of interaction of metal ions with macromolecules. These results can be also used in solving the problems related to the stability of the multichain structures of the polynucleotides. 


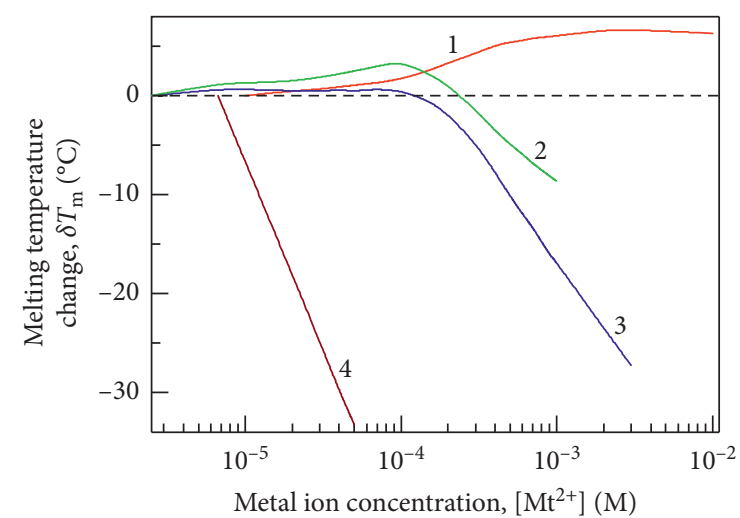

FIGURE 5: Changes in the thermal stability of poly(I:C) induced by various types of interactions with $\mathrm{Mt}^{2+}: 1$ : with phosphates; 2-4: with bases: $2: \mathrm{Ni}^{2+} ; 3: \mathrm{Cd}^{2+}$ and $\mathrm{Zn}^{2+} ; 4: \mathrm{Cu}^{2+}$.

\section{Conclusions}

It was found that $\mathrm{Mn}^{2+}$ and $\mathrm{Ca}^{2+}$ increase the thermal stability of the poly(I:C) due to the prevailing interaction with the phosphate groups of these polynucleotides. $\mathrm{Ni}^{2+}$, $\mathrm{Cd}^{2+}$, and $\mathrm{Zn}^{2+}$ decrease the thermal stability of the duplex due to their binding with nitrogenous bases that becomes prevailing at the concentration above $10^{-4} \mathrm{M}$. We revealed that the denaturation of poly $(\mathrm{I}: \mathrm{C})$ duplex structure in the presence of $\mathrm{Cu}^{2+}$ occurs already at concentrations of about $10^{-5} \mathrm{M}$. We have assumed that the thermodynamic reason for the different influence of metal ions on the stability of ds poly(I:C) is the difference in the binding constants of the ions to the double- and single-stranded conformations of the polynucleotides. The obtained results can be used in medicine, nanoelectronics, and biosensoring as well as in solving problems of genetic engineering.

\section{Data Availability}

The data used to support the findings of this study are available from the corresponding authors upon request.

\section{Conflicts of Interest}

The authors do not have any commercial or associative interest that represents any conflict of interest in connection with the work submitted.

\section{Acknowledgments}

This work has been supported by funding from the National Academy of Sciences of Ukraine (Grant 0120U100157).

\section{References}

[1] M. H. Shamsi and H.-B. Kraatz, "Interactions of metal ions with DNA and some applications," Journal of Inorganic and Organometallic Polymers and Materials, vol. 23, no. 1, pp. 4-23, 2013.

[2] S. D. Wettig, C.-Z. Li, Y.-T. Long, H.-B. Kraatz, and J. S. Lee, "M-DNA: a self-assembling molecular wire for nanoelectronics and biosensing," Analytical Sciences, vol. 19, no. 1, pp. 23-26, 2003.

[3] N. J. Gooderham and G. J. Mannering, "In vitro translational activity of messenger-RNA isolated from mice treated with the interferon inducer, polyriboinosinic acid.polyribocytidylic acid-polyribocytidylic acid," Biochemical Pharmacology, vol. 39, no. 5, pp. 865-871, 1990.

[4] S. Arnott and P. J. Bond, "Triple-stranded polynucleotide helix containing only purine bases," Science, vol. 181, no. 4094, pp. 68-69, 1973.

[5] D. Pak, Y. Kim, and Z. F. Burton, "Aminoacyl-tRNA synthetase evolution and sectoring of the genetic code," Transcription, vol. 9, no. 4, pp. 205-224, 2018.

[6] A. Malik, S. Parveen, T. Ahamad, S. M. Alshehri, P. K. Singh, and N. Nishat, "Coordination polymer: synthesis, spectral characterization and thermal behaviour of starch-urea based biodegradable polymer and its polymer metal complexes," Bioinorganic Chemistry and Applications, vol. 2010, Article ID 848130, 8 pages, 2010.

[7] N. Hadjiliadis and E. Sletten, Metal Complex-DNA Interactions, p. 524, John Willey \& Sons Publishing, New York, NY, USA, 2009.

[8] N. V. Hud, Nucleic Acid-Metal Ion Interactions, p. 433, Royal Society of Chemistry, London, UK, 2009.

[9] Z.-J. Tan and S.-J. Chen, "Nucleic acid helix stability: effects of salt concentration, cation valence and size, and chain length," Biophysical Journal, vol. 90, no. 4, pp. 1175-1190, 2006.

[10] K. A. Heinrichs, J. M. Price, A. Raley et al., "Probing the effects on the thermal stability of salmon sperm DNA in the presence of metal cations by measuring DNA melting temperatures," Advances in Biochemistry and Biotechnology, vol. 2017, no. 4, pp. 1-7, 2017.

[11] V. A. Sorokin, E. L. Usenko, and V. A. Valeev, " $\mathrm{Mg}^{2+}$ and $\mathrm{Ni}^{2+}$ ion effects on phase transitions in $\mathrm{AU}$ and $\mathrm{A} 2 \mathrm{U}$ under conditions close to physiological ones," IFMBE Proceedings, vol. 20, pp. 628-631, 2008.

[12] V. A. Sorokin, V. A. Valeev, E. L. Usenko, and V. V. Andrushchenko, "Divalent metal ion effect on helix-coil transition of high molecular weight DNA in neutral and alkaline solutions," International Journal of Biological Macromolecules, vol. 48, no. 2, pp. 369-374, 2011.

[13] V. A. Sorokin, V. A. Valeev, E. L. Usenko, and V. V. Andrushchenko, "DNA conformational equilibrium in the presence of $\mathrm{Zn}^{2+}$ ions in neutral and alkaline solutions," International Journal of Biological Macromolecules, vol. 50, no. 3, pp. 854-860, 2012.

[14] V. A. Sorokin, V. A. Valeev, E. L. Usenko, Y. P. Rakovsky, and V. V. Andrushchenko, "Specific features of $\mathrm{Zn}^{2+}, \mathrm{Co}^{2+}$ and $\mathrm{Ni}^{2+}$ ion binding to DNA in alkaline solutions," International Journal of Biological Macromolecules, vol. 55, pp. 137-141, 2013.

[15] S. J. E. Herrera and J. Š.and a., "Raman study of magnesium induced conversion of polyU.polyA duplexes to polyU.polyA.polyU triplexes," Spectroscopy, vol. 24, no. 3-4, Article ID 518738, pp. 445-448, 2010.

[16] C. M. Muntean, R. Misselwitz, and H. Welfle, "The Influence of $\mathrm{Mn}^{2+}$ on DNA structure in the presence of $\mathrm{Na}^{+}$ions: a Raman spectroscopic study," Spectroscopy, vol. 20, no. 5-6, pp. 261-268, 2006.

[17] H. Erbing, W. Hongfei, Y. Pin et al., "Studies on the interaction of $\mathrm{Cu}^{2+}$ and $\mathrm{Cd}^{2+}$ with poly(I:C)," Polyhedron, vol. 15, no. 12 , pp. 2067-2070, 1996.

[18] G. L. Eichhorn and E. Tarien, "Interaction of metal ions with polynucleotides and related compounds. IX. Unwinding and 
rewinding of poly $(\mathrm{A}+\mathrm{U})$ and poly $(\mathrm{I}+\mathrm{C})$ by copper(II) ions," Biopolymers, vol. 5, no. 3, pp. 273-281, 1967.

[19] G. N. Strunk and H. Diebler, "Binding of divalent metal ions to synthetic double-stranded polyribonucleotides," Journal of the Chemical Society, Dalton Transactions, vol. 13, no. 13, pp. 1929-1934, 1994.

[20] V. A. Sorokin, V. A. Valeev, E. L. Usenko, and V. A. Karachevtsev, " $\mathrm{Mg}^{2+}$ effect on stability of double-stranded polynucleotide formed by polyriboinosinic and polyribocytidilic chains," Biophysical Bulletin, vol. 2, pp. 68$72,2005$.

[21] D.-K. Chang and D. R. Kearns, "Distribution of $\mathrm{Mn}^{2+}$ ions around poly(rI).poly(rC)," Biopolymers, vol. 25, no. 7, pp. 1283-1297, 1986.

[22] R. Hajian and T. G. Huat, "Spectrophotometric studies on the thermodynamics of the ds-DNA interaction with irinotecan for a better understanding of anticancer drug-DNA interactions," Journal of Spectroscopy, vol. 2013, Article ID 380352, 8 pages, 2012.

[23] V. A. Sorokin, V. A. Valeev, G. O. Gladchenko, M. V. Degtiar, V. A. Karachevtsev, and Y. P. Blagoi, " $\mathrm{Mg}^{2+}$ ion effect on conformational equilibrium of poly A.2 poly $\mathrm{U}$ and poly A poly $\mathrm{U}$ in aqueous solutions," International Journal of Biological Macromolecules, vol. 31, no. 4-5, pp. 223-233, 2003.

[24] E. V. Chikhirzhina, S. J. Tatiana, and A. M. Polyanichko, "Interaction between chromosomal protein HMGB1 and DNA studied by DNA-melting analysis," Journal of Spectroscopy, vol. 2014, Article ID 387138, 5 pages, 2014.

[25] V. A. Sorokin, V. A. Valeev, G. O. Gladchenko, M. V. Degtiar, and Y. P. Blagoi, " $\mathrm{Ni}^{2+}$ ion effect of conformations on single-, double- and three-stranded homopolynucleotides containing adenine and uracil," Macromolecular Bioscience, vol. 1, no. 5, pp. 191-203, 2001.

[26] H. Krakauer and J. M. Sturtevant, "Heats of the helix-coil transitions of the poly A-poly U complexes," Biopolymers, vol. 6, no. 4, pp. 491-512, 1968.

[27] Y. P. Blagoi, V. L. Galkin, G. O. Gladchenko et al., Metal Complexes of Nucleic Acids in Solutions, p. 270, Naukova Dumka, Kiev, Ukraine, 1991.

[28] R. B. Martin and Y. H. Mariam, "Interactions between metal ions and nucleic bases, nucleosides, and nucleotides in solution," Metal Ions in Biological Systems, pp. 57-124, Marcel Dekker, New York, NY, USA, 1979.

[29] J. S. Lee, L. J. P. Latimer, and R. S. Reid, "A cooperative conformational change in duplex DNA induced by $\mathrm{Zn}^{2+}$ and other divalent metal ions," Biochemistry and Cell Biology, vol. 71, no. 3-4, pp. 162-168, 1993.

[30] Y. Y. Lurie, Handbook on Analytical Chemistry, p. 448, Chemistry, Moscow, Russia, 1989. 